УДК 539.434

(C) 2016

Приходько Р. П., кандидат технічних наук

Інститут проблем міцності імені Г. С. Писаренка

\title{
ТЕМПЕРАТУРНО-ЧАСОВИЙ ПІДХІД ДЛЯ ОЦІНКИ ДОВГОВІЧНОСТІ ВІДПОВІДАЛЬНИХ ЕЛЕМЕНТІВ КОНСТРУКЦІЙ
}

\section{Рецензент - доктор технічних наук О. В. Горик}

Поданий аналіз результатів екстраполяиії діаграм тривалої міџності за модифікованим методом базових діаграм. Показана ефективність запропонованих алгоритмів прогнозування під час розрахунку тривалої міцності на довговічність два $і$ більше порядки логарифмічної шкали часу. Уточнені області застосування відомих параметричних методів для прогнозування тривалої міцності матеріалів на основі експериментальних досліджень. Показано, що вони дають змогу екстраполювати час до руйнування до значень, які не більше, ніж в 10 разів перевищують наявні експериментальні дані з достатньою для технічних иілей точністю. Для розширення можливостей прогнозування до 300 тисяч годин і більше, виходячи з результатів випробувань обмеженої тривалості, запропонований модифікований метод базових діаграм. Запропонована лінійна залежність для апроксимації функиії нев'язки на основі базових діаграм. У разі неможливості приведення діаграм тривалої міцності до «єдиної» кривої параметри функиії нев'язки визначають із експериментальних даних для однісї ізотерми. В такому випадку ї̈ параметри є функціями від температури. Показані переваги такого підходу відповідно до параметричних співвідношень Ларсона-Міллера, Орра-Шербі-Дорна, Менсона-Саккопа, Труніна та інших за екстраполяції тривалої міциності на великі довговічності.

Ключові слова: модифікований метод базових діаграм, екстраполяція, діаграми тривалої міцності, параметричні методи.

Постановка проблеми. 3 кожним роком стає все більш гострішим питання оцінки та подовження ресурсу відповідальних елементів конструкцій тривалого використання. Достовірне прогнозування довговічності вимагає наявності достатньо повної інформації про поведінку матеріалу в різних умовах термосилового навантаження. Основою для проведення необхідного аналізу і в подальшому прийняття відповідних рішень являються експериментальні дані по довговічності і діючому напруженню. В реальних умовах отримати відповідні експериментальні результати $\epsilon$ досить трудомісткою роботою, оскільки дослідження може проводитися від кількох днів до десятків років, що вимагає перш за все великих затрат. Отже, дослідження по уточ- ненню відомих підходів та розробка нових моделей по екстраполяції діаграм тривалої міцності є актуальною задачею.

Аналіз останніх досліджень і публікацій, у яких започатковано розв'язання проблеми. До найбільш відомих методів екстраполяції діаграм тривалої міцності відносять температурночасові співвідношення Ларсона-Міллера, ОрраШербі-Дорна, Менсона-Хеферда і Труніна [5-8]. Ці рівняння дають можливість отримати єдину залежність між напруженням, часом до руйнування i температурою випробування, що дає змогу вирішувати задачі як інтерполяції, так i екстраполяції, виходячи 3 відомих експериментальних даних по довговічності в широкому інтервалі температур.

В основі параметричних методів лежить гіпотеза єдиної кривої, у відповідності до якої всі діаграми тривалої міцності зводяться до «єдиної» усередненої кривої. Така функція, що апроксимує результати експериментів, може бути подана у вигляді:

$$
\sigma=F_{1}(\eta) \text { або } \tau=F_{2}(\eta)
$$

де $\sigma$ - діюче напруження, $\tau$ - довговічність матеріалу при $\sigma=$ const, $\eta$ - деякий параметр, що залежить від двох змінних, як правило $\eta=\eta(T, \tau), \quad T$ - абсолютна температура. У випадку складного напруженого стану під $\sigma$ мають на увазі еквівалентне напруження [3, 4].

Параметричні методи можуть використовуватися для опису механічної поведінки середовища за певних обмежень на вид діаграми тривалої міцності матеріалів. Ці обмеження пов'язані 3 тим, що дані методи були створені для інтерполяційної оцінки експериментальних даних. Тому застосування їх для екстраполяції тривалої міцності є доцільним на невеликі довговічності, що відповідають не більше 1 порядку логарифмічної шкали часу. Це досить легко пояснити, побудувавши відповідну апроксимаційну функцію по кожному з методів.

Дещо інший підхід у випадку оцінки тривалої міцності має аналізований нами метод базових діаграм В. В. Кривенюка [1]. Основою його про- 


\section{TЕХНІЧНІ НАУКИ}

гнозування $є$ визначені базові функції, що вважаються однотипними і незмінними для всіх відомих матеріалів. Визначення розрахункових коефіцієнтів відповідно до даного методу здійснюється на основі статистичної обробки експериментальних і базових діаграм. Застосування даного методу в порівнянні 3 параметричними дає можливість здійснювати прогнозування на більшу довговічність, що становить близько двох порядків в логарифмічній системі координат. Інтерполяційний аналіз за методом базових діаграм є більш інформативним; по зміні розрахункового параметра $\beta$ можна робити висновки про характер зміни поведінки матеріалу протягом усього експериментального дослідження. Хоча даний метод прогнозування тривалої міцності має чимало переваг, він не став широко розповсюдженим в інженерній практиці через свій головний недолік - незавершеність досліджень по визначенню інтервалів температур і діючих напружень, в межах яких можуть застосовуватися його визначальні параметри під час прогнозування довговічності жароміцних матеріалів.

Метою дослідження $\epsilon$ розробка і удосконалення методів екстраполяції тривалої міцності в широких діапазонах напружень і температур.

Завданням є викладення чіткого алгоритму оцінки довговічності відповідальних елементів конструкцій, виходячи з обмеженої експериментальної вибірки.

Методика проведення досліджень відповідає вимогам нормативних документів по тривалій міцності і повзучості.

У роботі [2] представлений новий метод прогнозування тривалої міцності. Запропоновано два варіанти такого підходу. Відповідно до першого: функції нев'язки є інваріантними до температури, в другому випадку - вони є функціями температури. Такий підхід дає змогу більш точно проводити екстраполяцію тривалої міцності та відповідно визначати залишковий ресурс конструкції.

Результати дослідження. Як було сказано раніше, за наявності експериментальних результатів у широкому діапазоні напружень і температур параметричні методи дають можливість із задовільною точністю аналізувати і екстраполювати тривалу міцність. Однак у випадку, коли ми маємо обмежену базу експериментів, прогнозування ними призводить до значних похибок або взагалі є неможливим.

Для підтвердження вище зазначеного представимо результати по екстраполяції тривалої

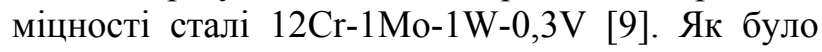
показано в [2], під час прогнозування тривалої міцності за допомогою параметричних підходів використовують їх лінійні моделі. Точність опису тривалої міцності великою мірою залежить від точності, з якою були знайдені константи $A_{n}$. У таблиці 1 подані результати прогнозування напруження на довговічності 0,8-1,5 порядки логарифмічної шкали часу.

Зазначимо, що відсутність екстрапольованої величини для відповідного методу свідчить про неможливість обрахунку їі для наведеного порядку прогнозування на основі поданих експериментальних даних. Водночас порядок прогнозування становив лише 1,4 в логарифмічній системі координат.

На рисунку 1 зафарбованими маркерами представлена область експериментальних значень, 3 використанням якої було проведено разрахунок відповідних апроксимаційних характеристик по методу Ларсона-Міллера.

1. Результати по екстраполяції тривалої міцності сталі $12 \mathrm{Cr}-1 \mathrm{Mo-1W-0,3V}$

\begin{tabular}{|c|c|c|c|c|c|c|c|c|}
\hline $\mathrm{T},{ }^{\circ} \mathrm{C}$ & 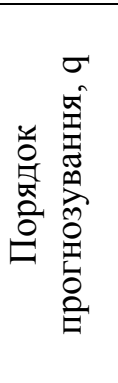 & 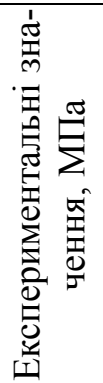 & 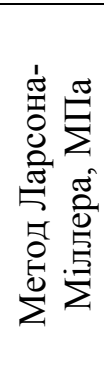 & 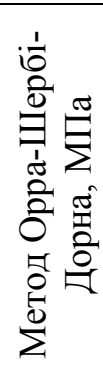 & 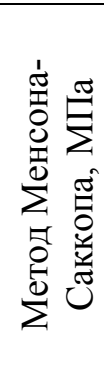 & 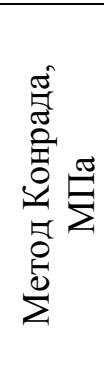 & 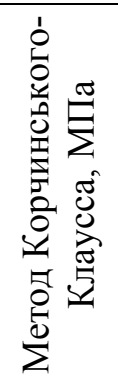 & 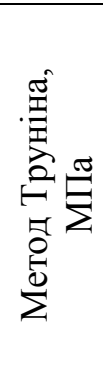 \\
\hline 500 & 1,5 & 216 & 319,3 & 316,6 & 311,5 & 327,4 & 380 & 325 \\
\hline 550 & 0,8 & 137 & 225,9 & 224,3 & 226,7 & 224,3 & 247,2 & 222,9 \\
\hline 600 & 1,4 & 47 & - & - & - & $-25,4$ & 49,2 & - \\
\hline
\end{tabular}




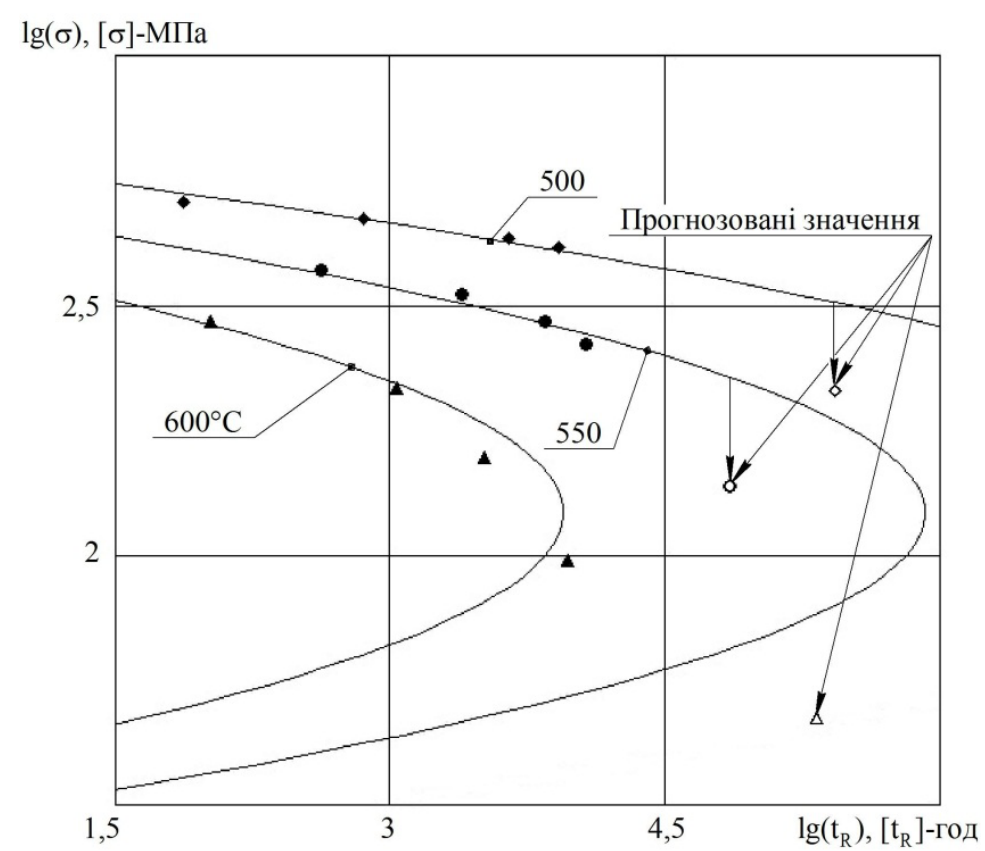

\section{Рис. 1. Інтерполяційний аналіз кривих тривалої міцності сталі $12 \mathrm{Cr}-1 \mathrm{Mo-1}$ W-0,3V методом Ларсона-Міллера}

Представлені результати розраховані 3 використанням лінійних моделей:

a) Ларсона-Міллера [6]

$\lg (\tau)=A_{0}+A_{1} T^{-1}+A_{2} T^{-1} \lg (\sigma)+A_{3} T^{-1} \lg ^{2}(\sigma)$,

б) Труніна [5]

$\lg (\tau)=2 \lg (T)+\left(A_{0}+A_{1} \lg (\sigma)+A_{2} \sigma \cdot T^{-1}+A_{3} T^{-1}\right) \cdot \lg (e)$,

де $\tau$-довговічність, $\quad T$ - температура, $A_{n}$ - розрахункові константи $(n=0,1,2,3$. $)$.

Незафарбовані маркери визначають точки діаграми тривалої міцності, для яких здійснювався екстраполяційний аналіз.

Як бачимо 3 малюнку, характер поведінки отриманої функції за обраним методом прогнозування діаграм тривалої міцності унеможливлює отримання коректного результату у випадку великих термінів довговічності.

Відсутність розрахункових екстраполяційних значень напружень для інших методів у представленій таблиці 1 пояснюється аналогічно.

У свою чергу модифікований метод базових діаграм дає змогу проводити достовірне прогнозування на довговічність 2,5-3 порядки логарифмічної шкали часу. Перший варіант моделі базується на гіпотезі, що $є$ основою для усіх параметричних співвідношень [5-8], а саме гіпотезі об'єднання всіх кривих тривалої міцності при різних температурах в одну усереднену.

Якщо нам відомі експериментальні результати по тривалій міцності жароміцного матеріалу у випадку деяких фіксованих температур, то використовуючи базові діаграми, ми можемо в першому наближенні обчислити величини напружень для заданої довговічності. Базові діаграми описуються співвідношенням

$$
\lg \left(\widetilde{\sigma}\left(p_{i}, \tau\right)\right)=3,6-p_{i} \cdot\left[12+\lg (\tau)+0,1 \cdot \lg ^{2}(\tau)\right]
$$

де $\lg \left(\widetilde{\sigma}\left(p_{i}, \tau\right)\right)$ - напруження по базовій діаграмі, $\tau$ - довговічність, $p_{i}$ - параметр, що залежить від координати точки, з якої здійснюється прогнозування.

Уточнення першого наближення здійснюється за формулою функції нев'язки, яка залежить від параметра $\beta$, що визначає котангенс нахилу до осі ординат відрізка діаграми тривалої міцності, що проходить через дві точки $\left\{\lg \left(\sigma_{i}\right), \lg \left(\tau_{i}\right)\right\}$ i $\left\{\lg \left(\widetilde{\sigma}\left(p_{i}, \tau_{n}\right)\right), \lg \left(\tau_{n}\right)\right\}$. Під час прогнозування 3 точки $i$ в точку $n$ значення функції нев'язки визначається за такою формулою:

$$
\begin{array}{r}
\Delta_{\text {in }}=\lg \left(\sigma_{i}\right)-\lg \left(\widetilde{\sigma}\left(p_{i}, \tau_{n}\right)\right), \\
(i=1,2,3, \ldots, n-1) .
\end{array}
$$




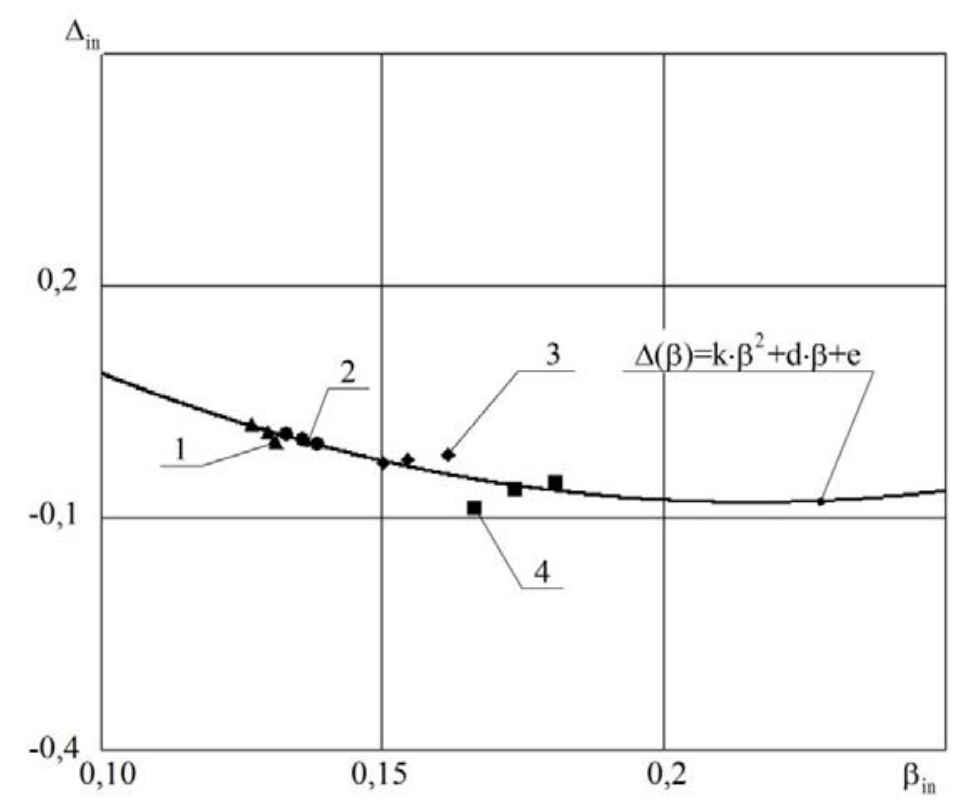

Рис. 2. Графічна інтерпретація функцї̈-нев'язки сталі 18Cr-12Ni-Mo $1-600{ }^{\circ} \mathrm{C}, 2-650^{\circ} \mathrm{C}, 3-700^{\circ} \mathrm{C}, 4-750^{\circ} \mathrm{C}$

2. Результати по екстраполяції тривалої міцності сталі 18Cr-12Ni-Mo

\begin{tabular}{|c|c|c|c|c|c|}
\hline$T,{ }^{\circ} C$ & $\begin{array}{c}\text { Порядок } \\
\text { прогнозування, q }\end{array}$ & $\sigma_{\text {експ }}$, МПа & $\begin{array}{c}\sigma_{\text {Ммьд }}, \\
\text { МПа }\end{array}$ & $\begin{array}{c}\sigma_{\text {Л-м }}, \\
\text { МПа }\end{array}$ & $\begin{array}{c}\sigma_{\text {Труніна }}, \\
\text { МПа }\end{array}$ \\
\hline 600 & 1,2 & 127 & 130,5 & 134,8 & 132,4 \\
\hline 650 & 1,6 & 53 & 80,1 & 89,4 & 85,5 \\
\hline 700 & 2,1 & 22 & 30,3 & 33,9 & 34,1 \\
\hline 750 & 1,4 & 18 & 22,9 & 23,1 & 27,5 \\
\hline
\end{tabular}

Розрахунок характеристичного визначального параметра здійснюємо за співвідношенням

$$
\beta_{i n}=\frac{\lg \left(\sigma_{i}\right)-\lg \left(\widetilde{\sigma}\left(p_{i}, \tau_{n}\right)\right)}{\lg \left(\tau_{i}\right)-\lg \left(\tau_{n}\right)}, \quad(i=1,2,3, \ldots, n-1) .
$$

Будемо вважати, що вид функції-нев'язки не змінюється під час опису діаграми тривалої міцності. Вважаємо, що параметри $k, d, e$ функціїнев'язки $\Delta(\beta)=k \cdot \beta^{2}+d \cdot \beta+e \in$ інваріантними до температури. На рисунку 2 подано графічну інтерпретацію функції-нев'язки та опис ії обраною апроксимаційною функцією.

Як бачимо у даному випадку під час апроксимації функції-нев'язки ми використали поліном другого порядку. Користуючись вище зазначеними співвідношеннями, отримуємо значення прогнозованих напружень у разі заданої довговічності. В таблиці 2 подані результати екстраполяції тривалої міцності жароміцного матеріалу 18Cr-12Ni-Mo [10]. 3 представленого порівняльного аналізу досить чітко видно переваги запропонованої методики екстраполяції діаграм три- валої міцності. В ГОСТах, які регламентують проведення досліджень на повзучість і тривалу міцність, не вказано потрібну кількість зразків, оскільки вважається, що всі вони однотипні, структурні перетворення, що можуть проходити, однакові, матеріал повністю ізотропний.

Тому часто проведення експериментів на тривалу міцність обмежується кількома дослідними зразками в одному чи двох температурних інтервалах. Для таких випадків параметричні методи не можуть бути використані. Оскільки під час апроксимаційного аналізу ми не можемо знайти достовірних розв'язків визначальних параметрів.

Другий варіант запропонованого нами підходу модифікованого методу базових діаграм, - коли характеристичні параметри функції-нев'язки вважаємо залежними від температури, дає змогу досить легко і точно проводити задовільну екстраполяцію у випадку $T=$ const .

На рисунку 3 представлено можливий вигляд функцій нев'язки для кожної температури сталі $1,25 \mathrm{Cr}-0,5 \mathrm{Mo}-\mathrm{Si}$ [11]. У даному випадку ми обмежилися простими лінійними залежностями. 


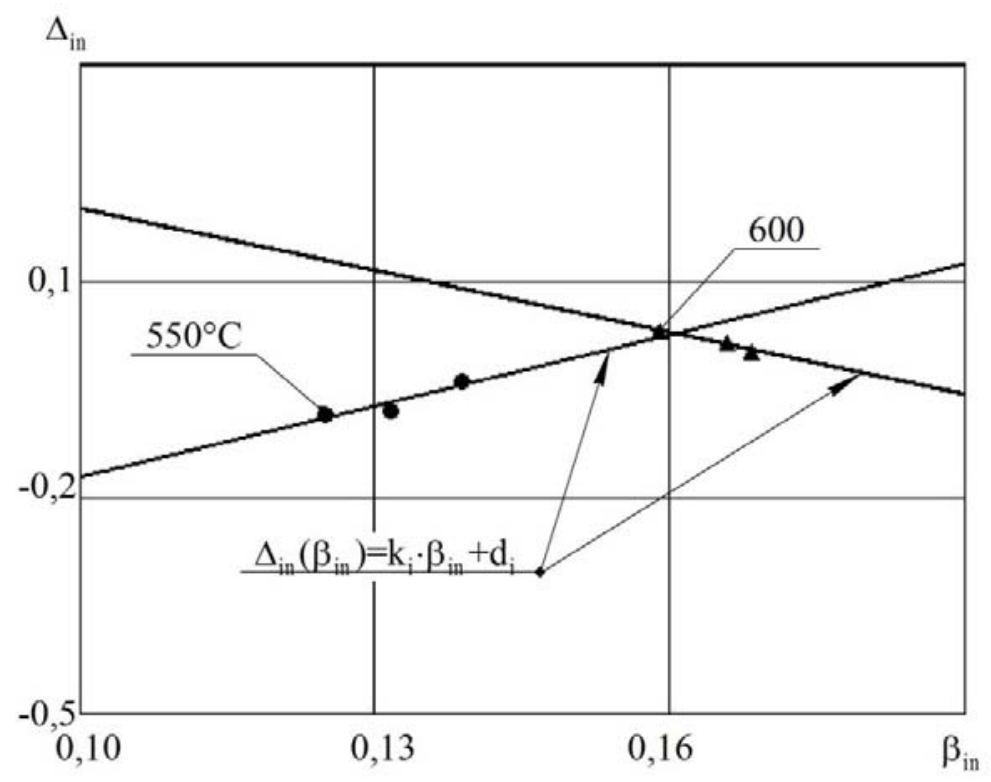

Рис. 3. Графічна інтерпретація функцій нев'язки для кожної ізотерми сталі 1,25Cr-0,5Mo-Si

3. Результати по екстраполяції тривалої міцності сталі 1,25Cr-0,5Mo-Si

\begin{tabular}{|c|c|c|c|c|c|c|c|c|}
\hline \multirow[t]{2}{*}{$\stackrel{+}{{ }^{\circ} \mathrm{C}}$} & \multirow[t]{2}{*}{$\begin{array}{c}\text { Порядок } \\
\text { прогнозування, } \\
\text { q }\end{array}$} & \multirow[t]{2}{*}{$\sigma_{\text {ексn }}$, МПа } & \multirow[t]{2}{*}{$\begin{array}{c}\sigma_{J-M}, \\
\text { МПа (1) }\end{array}$} & \multirow[t]{2}{*}{$\begin{array}{l}\sigma_{\text {Труніна }}, \\
\text { МПа (2) }\end{array}$} & \multirow[t]{2}{*}{$\begin{array}{l}\sigma_{\text {ммьд }}, \\
\text { МПа (3) }\end{array}$} & \multicolumn{3}{|c|}{$\delta_{i}=\frac{\sigma_{\text {ексn }}-\sigma_{\text {розр }}}{\sigma_{\text {ексn }}}, \mathbf{\%}$} \\
\hline & & & & & & (1) & (2) & (3) \\
\hline 550 & 2,3 & 61 & 67 & 64 & 62 & 9,8 & 4,9 & 1,6 \\
\hline 600 & 1 & 29 & 55 & 54 & 43 & 89,7 & 89,7 & 48,3 \\
\hline
\end{tabular}

Як бачимо з представленого графіку, визначені параметри функції нев'язки змінюються в досить вузькому інтервалі для кожної ізотерми, що вказує на можливість задовільного прогнозування. В таблиці 3 наведені результати екстраполяції для вище представленого матеріалу. Потрібно відмітити, що під час прогнозування параметричними методами враховувалися експериментальні дані по двох ізотермах, а по модифікованому методу базових діаграм кожна крива тривалої міцності характеризувалася окремо.

Отже, аналізуючи вищевикладене, можна говорити, що використання другого варіанту модифікованого методу базових діаграм дає можливість здійснювати достовірне прогнозування

\section{БІБЛІОГРАФІЯ}

1. Кривенюк В. В. Интерполяционный анализ особенностей длительного разрушения хромоникелевых и хромомолибденовых сталей / В. В. Кривенюк, Д. С. Авраменко, Р. П. Приходько // Пробл. прочности. - 2013. - №2. - С. 91-96.

2. Кучер Н. К. Прогнозирование высокотемпературной длительной прочности материалов / тривалої міцності для обмеженої експериментальної вибірки (1-2 ізотерми).

Висновок. Проаналізовано недоліки параметричних методів прогнозування та вказано на обмеження їх використання під час прогнозування тривалої міцності жароміцних матеріалів. Продемонстровано ефективність запропонованого варіанту модифікованого методу базових діаграм за екстраполяції тривалої міцності в порівнянні з відомими підходами у випадку прогнозування на великі довговічності. Представлений порівняльний аналіз прогнозування довговічності на основі обмеженої (1-2 ізотерми) експериментальної бази даних під час використання різних методик розрахунку.

Н. К. Кучер, Р. П. Приходько // Пробл. прочности. -2013 . - №5. - С. 5-12.

3. Локощенко А. М. Моделирование процесса ползучести и длительной прочности металлов / А. М. Локощенко. - М. : МГИУ. - 2007. - 264 с.

4. Работнов Ю. Н. Ползучесть элементов конструкций / Ю. Н. Работнов. - М. : Наука, 
1966. - $752 \mathrm{c}$.

5. Трунин И. И. Механическое уравнение состояния металлических материалов и прогнозирование характеристик жаропрочности / И. И. Трунин // Пробл. прочности. - 1976. - №9. - С. 9-13.

6. Larson F. R. Time temperature relationship for rupture and creep stresses / F. R. Larson, J. Miller // Trans. ASME. - 1952. - V. 74, №5. - P. 765-775.

7. Manson S. S. A linear time-temperature relation for extrapolation of creep and stress rupture data / S. S. Manson, A. M. Haferd // NASA TN 2890. - 1953.

8. Orr R. L. Correlation of rupture data for metals at elevated temperatures / R. L. Orr, O. D. Sherby,
J. E. Dorn // Trans. ASM. - 1954. - V.46. - P. 113-128.

9. Data sheets on the elevated-temperature properties of $12 \mathrm{Cr}-1 \mathrm{Mo}-1 \mathrm{~W}-0.3 \mathrm{~V}$ heat-resisting steel bars for turbine blades (SUH 616-B) // NRIM Creep Data Sheet. - 1998. - №10B. - P. 1-44.

10. Data sheets on the elevated-temperature properties of $18 \mathrm{Cr}-12 \mathrm{Ni}-\mathrm{Mo}$ stainless steel tubes for boilers and heat exchangers (SUS 316H TB) // NRIM Creep Data Sheet. - 2000. - №6B. - P. 1-36.

11. Data sheets on the elevated-temperature properties of $1.25 \mathrm{Cr}-0.5 \mathrm{Mo}-\mathrm{Si}$ steel tubes for boilers and heat exchangers (STBA 23) // NRIM Creep Data Sheet. - 2001. - №2B. - P. 1-32. 